\title{
Evaluating Land Use/Land Cover Change and Its Socioeconomic Implications in Agarfa District of Bale Zone, Southeastern Ethiopia
}

\author{
Teha Turi, Hussien Hayicho*, Haji Kedir \\ Department of Geography and Environmental Studies, Maddawalabu University, Bale-Robe, Ethiopia \\ Email: *hussienhayicho2000@gmail.com
}

How to cite this paper: Turi, T., Hayicho, H. and Kedir, H. (2019) Evaluating Land Use/Land Cover Change and Its Socioeconomic Implications in Agarfa District of Bale Zone, Southeastern Ethiopia. Journal of Environmental Protection, 10, 369-388. https://doi.org/10.4236/jep.2019.103022

Received: December 9, 2018

Accepted: March 8, 2019

Published: March 11, 2019

Copyright ( 2019 by author(s) and Scientific Research Publishing Inc. This work is licensed under the Creative Commons Attribution International License (CC BY 4.0).

http://creativecommons.org/licenses/by/4.0/

\begin{abstract}
A systematic analysis of land use/cover change is so decisive to exactly understand the extent of change and take essential measures to curb down the rate of changes and protect the land cover resources sustainably. This land use/land cover change study was conducted in Agarfa district of Bale zone, Oromia Regional State, Southeastern Ethiopia. The objectives of this study were to evaluate the trends, drivers and its socio-economic and environmental implication in study area. A descriptive research method was employed to achieve the intended objectives of the study. In the three years (1976, 1995, and 2014) Landsat Satellite images and socio-economic survey were the main data sources for this study. ERDAS Imagine and Arch-GIS tools were used to classify and generate land use/land cover maps of the study area. Survey questionnaires, key informant interviews, and field observation were employed to obtain information on drivers and its socio-economic and environmental implication in the district. The results show that the land use/land cover of the study area had changed dramatically during the period of 38 years. A rapid loss of forest land and shrub land cover in the landscape took place between 1976 and 2014. Conversely, agriculture and grazing lands were increased by $30 \%$ and $42 \%$ respectively at the expense of the lost land use/land cover types. Forest land is the most converted cover type during the entire study period. In the 38 years, forest lands diminished by over $65 \%$ of the original forest cover that was existed at the base year (1976). Local climate change, declining agricultural productivity and livestock quantity and quality and scarcity of fuel wood and constructional materials were some of the socio-economic and livelihood impacts of land use and land cover change of the study area. Thus, this finding affords information to land users and policy makers on extent of the change and social forces leading to this changes and its subsequent implication on local socio-economic and environmental conditions of the study area.
\end{abstract}




\section{Keywords}

Land Use/Land Cover Change Evaluation, Image Classification, Impacts of Land Use Land Cover Change, Agarfa District, GIS and Remote Sensing

\section{Introduction}

Land use/cover change is a dynamic, wide-spread and fast-tracking process caused by natural phenomena and exacerbated by human actions, which in turn drives changes that would influence humans. Land use/cover conversions to farmland, and settlement and to urban development reduce the extent of lands accessible for food and timber production. Soil erosion, salinization, desertification and other soil degradations allied with intensive agriculture and deforestation decrease the quality of land resources and future agricultural productivity [1].

Land use alteration trends in many developing countries are both tremendously swift and the direction of changes and rates are influx. Africa is said to have the fastest deforestation in the world as a result of dependence on the primary resources [2]. Increasing population pressure across Sub-Saharan Africa has been responsible to increase in cultivation and grazing intensity [3]. This has attributed to huge deforestation and conversion of natural habitats to farmlands and settlements with consequences on biodiversity and land degradation. Land use in East Africa has changed rapidly over the last half century: expansion of mixed crop-livestock systems in to former grazing land and other natural areas and intensification of agriculture are the two largest changes that have been noticed [4].

Ethiopia is a country characterized by rapid environmental changes and modifications accredited to different adverse human actions, like expansion of farm plots at the expense of vegetated lands, substantial fuel wood and charcoal production, overgrazing and encroachment of farmlands into vegetated lands. Like other parts of the country, the Bale Mountains Eco-region has been affected by human activities such as deforestation, overgrazing, illegal logging and hunting [5]. Residents in the eco-region engage in deforestation to acquire land for crop production, for livestock grazing and to fulfill their demand of timber and fire wood. For example, deforestation rate in the Bale Mountains ranged from $1 \%$ to 8\%, between 1986 and 2009 with an average rate of 3.7\% per annum [6]. This deforestation rate is about four times the $1 \%$ country-wide forest loss [7]. This implies that forest in the Bale Eco-region is shrinking at an alarming rate.

A study in the other parts of the Bale Mountains such as Herenna catchment showed a significant decline in dense forest cover from $26.8 \%$ to $6.2 \%$ and agricultural land increased from $11.1 \%$ to $17.7 \%$ [8]. It is also estimated that the montane forest which comprises more than $40 \%$ of the total area of BMNP has been lost at an average annual rate of $3.74 \mathrm{~km}^{2}$ between 1973 and 2005 [9]. Ac- 
cording to [10] between 1973 and 2008 a total of $26.65 \%$ of the original area of Afromontane grasslands, a total of $15.41 \%$ of upper montane forest, and a total of $14.58 \%$ of Afromontane dwarf shrubs and herbaceous formations were converted to agricultural lands and hence, agricultural fields increased from $1.71 \%$ to $9.34 \%$.

Most of these studies focused on the assessment of biophysical (trends and extent) condition of LULCC over time using remote sensing data and expert opinion. However, these studies missed to integrate socio-economic survey to better understand the causes and impacts of the change.

Analysis of land use/land cover change at a local scale is vital to comprehend about the complex relationships between environmental, economic and social drivers that induce changes and the likely impacts at local level. Moreover, a systematic analysis of land use/cover change is so decisive to exactly understand the extent of change and take essential measures to curb down the rate of changes and protect the land cover resources sustainably [11]. In the study area, there are observable land cover change problems which include widespread deforestation for several different purposes such as, encroachment of agriculture and settlements into forest areas, charcoal and construction materials production and severe soil erosion along hilly slopes. However, there are scarce local scale land use/cover change studies in southeastern Ethiopia in general and Agarfa district in particular. As the study area borders BMNP which is one of the world's hotspot areas that harbors variety of endemic animal and plant species, evaluation of the impacts of land use/cover change on these local ecosystem and livelihoods in this area is relevant and timely. Moreover, information on land use/cover change and its possibilities for ideal use is essential for the selection, planning and implementation of land use schemes to meet the increasing demands of basic human needs and wellbeing. Thus, the study evaluated the spatio-temporal pattern changes of land use/land cover with associated causes of alteration in the study area. This information also assists in monitoring the changes in land use resulting from changing demands of increasing human population [12].

The main objective of this study is to evaluate the spatio-temporal changes of land use/land cover over the four decades (1976-2014) in Agarfa District.

Specific objectives of this study were:

1) To classify and quantify the land use/land cover changes in the study area.

2) To identify the major driving forces of the land use/land cover changes.

3) To assess socio-economic implications of the observed land use/land cover changes.

\section{Materials and Methods}

Agarfa district is found in the Bale Administrative Zone of Oromia Regional State, in Southeastern part of Ethiopia. It lies between $7^{\circ} 8^{\prime} \mathrm{N}$ to $7^{\circ} 28^{\prime} \mathrm{N}$ latitude and $39^{\circ} 31^{\prime} \mathrm{E}$ to $40^{\circ} 5^{\prime} \mathrm{E}$ longitude (Figure 1). Its surface area is about $1216.34 \mathrm{~km}^{2}$ (Figure 1). 


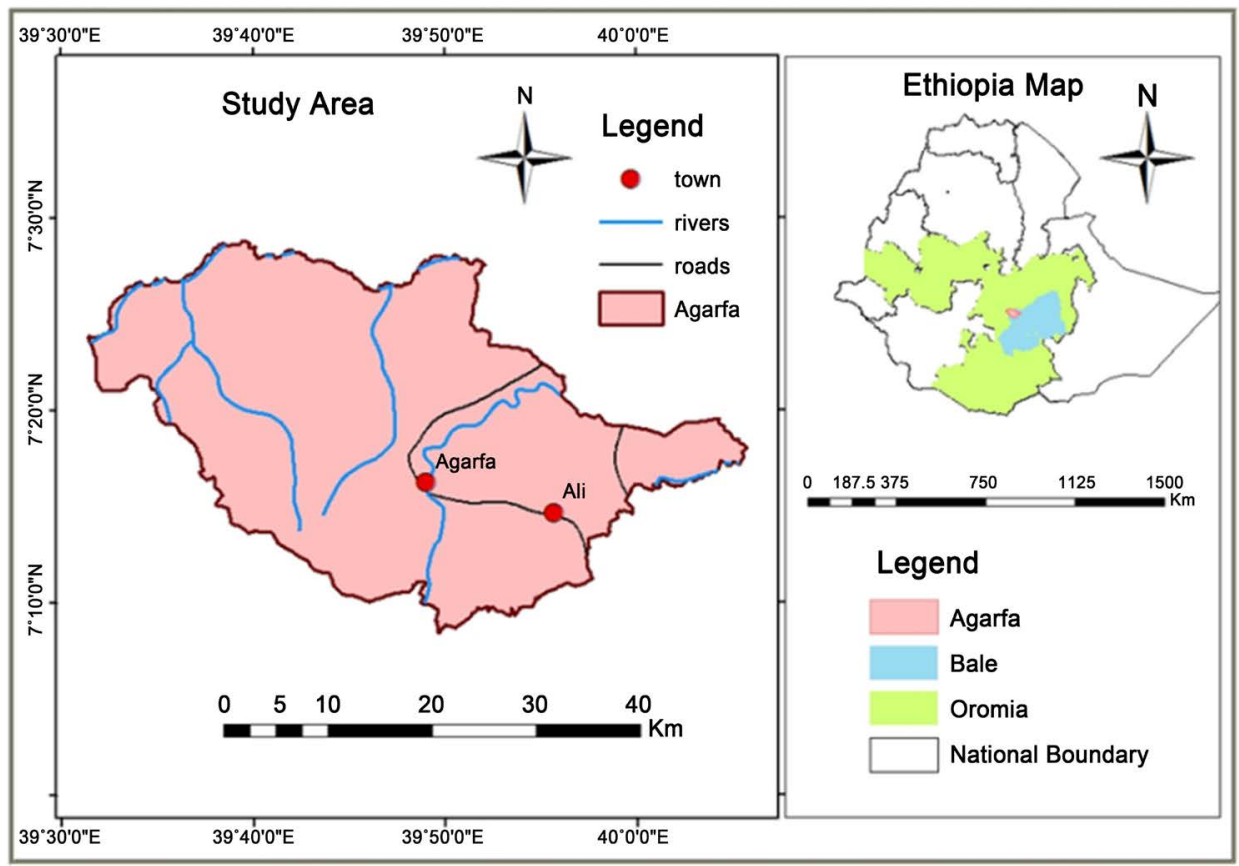

Figure 1. Location map of the study area.

The elevation of Agarfadistrict ranges from $1400 \mathrm{~m}$ to $3800 \mathrm{~m}$ above mean sea level (a.m.s.l). About $61 \%$ of the district is plain with slope ranging from 0 to 8 degrees and the majority of this area lies in the southeastern and western parts of the study area. Wabeshabelle river gorges and related rugged terrains make about $31 \%$ of the district. Mountain ranges comprise about $8 \%$ of the district which lies along southwestern corridor of the district that borders Bale Mountains National Park [13]. The district is drained by Wabeshebelle tributaries, Weybriverand other perennial rivers that drain the district are Wuchima, Makkalla, Fawwa, Tugumma. Agarfa district falls within three traditional agro-climatic zones, vernacularly termed as Gamoji (hot), Bada-dare (temperate), and Bada (cold). Mean maximum and mean minimum temperatures are $25^{\circ} \mathrm{C}$ and $10^{\circ} \mathrm{C}$ respectively. The amount of maximum and minimum rainfall received in the area ranges between $1200 \mathrm{~mm}$ and $400 \mathrm{~mm}$, respectively. The dominant soil types in the district include: vertisols, cambisols, luvisols and lithosols that are derived from tertiary volcanic rocks [13]. The common natural vegetation types in the district comprise of juniper and podocarpus trees, bamboos, scattered woods, shrubs and bushes along relatively lower altitudes. The district is also endowed with varieties of wild lives which include Bush back, monkey, Columbus monkey, hyena, jackal, apes, different species of birds, and varieties of reptiles and amphibians.

About $87.36 \%$ of the population lives in rural areas whose livelihood is predominantly dependent on rain-fed, subsistence agriculture along with rearing of livestock. The major crops produced are barley, wheat and teff, maize, beans, and peas. The crops which are produced in the drier, low land areas are mainly maize, sorghum, and teff [14]. 


\subsection{Data Sources}

The three years satellite images were used to scrutinize the spatio-temporal changes in land use/land cover in the study area (Table 1). Landsat satellite images of Agarfa district, the Landsat MSS for the time period 1976 was obtained from Global Land Cover Facility (GLCF), while Landsat TM7 and Landsat $\mathrm{ETM}^{+} 8$ for the periods 1995 and 2014, respectively were acquired from USGS Global Visualization Viewer an Earth Resources Observation and Science Center (EROS). Apart from satellite images, field observation and questionnaire were conducted. Other secondary sources of data such as topo sheet of the study area, district annual reports, and other published and unpublished materials were consulted.

\subsection{Data Processing Procedures}

Base map of the study area was prepared from the topographic map on 1:50,000 scale. Various permanent features like roads, rivers or any other land based features were transferred to the base map. The administrative district boundary map was brought to Universal Transverse Mercator (UTM) project in zone 37 and later the satellite imageries were clipped with the administrative boundary of Agarfa. Thereafter, preliminary interpretation of satellite data was carried out and a preliminary interpretation key was prepared. The preliminary interpreted maps thus prepared were taken to field for ground checking. Initially three dates (1976, 1995, and 2014) satellite imageries were downloaded from their respective sources. To conform the pixel grids and remove any geometric distortions in the imagery, the first Landsat MSS of 1976 image was registered and geo-referenced to the WGS_1984_UTM_Zone 37 coordinate system based on 1:50,000 scale topographic maps. Then, each of the Landsat TM of 1995 and ETM ${ }^{+}$of 2014 images were registered to the 1976 image using image to image rectification technique. Then, image enhancement was undertaken in order to enhance the quality of the image and readability of the features.

The preparation of thematic maps from the digital satellite data was carried out by using ERDAS Imagine ver. 2014 and ArcGIS ver. 10.3 software and platforms. Then field visit to site was carried out to obtain ground control points using GPS for ground truth data collection.

\subsubsection{Image Classification}

Classification is the hypothetical representation of a real life situation using easily defined and well delineated criteria. Classification schemes are usually hierarchically organized into numerous levels with various degrees of details and have certain criteria to differentiate land cover categorization from one another [15].

According to [16], more common land use/land cover classification schemes are: Anderson, national land cover data and FAO land cover classification systems. Consequently, for this study, FAO land cover classification system in Table 2 was employed for classifying and setting land use/land cover types of the 
study area.

supervised classification method was used with maximum likelihood classifier decision rule assisted by ground control points (GCPs) collected during field surveys for the latter two periods of images while the researcher's prior knowledge and different physical features patterns recognition system was used for the former one(2014). Figure 2 shows spatial distribution of GCPs draped over Google Earth. In this study, a total of 60 ground truth points collected during the field survey were used for the classification (30) and validation (30) of $2014 \mathrm{im}$ age. For the classification and validation of image in 1976 and 1995 periods, aerial photographs of 1957 and 1982 were used to generate random points of 200 and 232, respectively, and half these were used for training classification while the remaining half were used for the accuracy assessment. A representation of the regions of interest known as the training sites were digitized giving them different IDs and unique colours.

Training areas for all spectral classes were developed by composing each information class to be identified by the classifier. Since there was more than one

Table 1. Satellite data.

\begin{tabular}{ccccc}
\hline Satellite \& Sensors & Path/Row & Resolution & Acquisition Date & Data type \& Bands \\
\hline Landsat ETM ${ }^{+} 8$ & $167 \& 168 / 055$ & $30 \mathrm{~m}$ & 11 Jan \& 20 Dec 2014 & Digital $(1,2,3, \cdots, 9)$ \\
Landsat TM7 & $167 \& 168 / 055$ & $30 \mathrm{~m}$ & 14 \& 27 Jan 1995 & Digital $(1,2,3,4,5,7)$ \\
Landsat MSS & $180 / 055$ & $60 \mathrm{~m}$ & 24 Jan 1976 & Digital $(4,5,6,7)$ \\
\hline
\end{tabular}

Table 2. Description of the land use/land cover categories.

\begin{tabular}{cl}
\hline Land use/cover types & \multicolumn{1}{c}{ Land use/cover description } \\
\hline Agriculture (crop land) & $\begin{array}{l}\text { Areas of land under cultivation and rural settlements with some woods } \\
\text { around homesteads and in farm lands. }\end{array}$ \\
Forest land & $\begin{array}{l}\text { Areas of land covered by trees predominantly forming closed or nearly } \\
\text { closed canopies. Land dominated by trees }>5 \mathrm{~m} .\end{array}$ \\
Shrub land & $\begin{array}{l}\text { Land area covered by small trees, bushes or shrubs in some areas } \\
\text { mixed with grasses. }\end{array}$ \\
Grazing land & $\begin{array}{l}\text { Areas of land where grasses are the dominant natural vegetation } \\
\text { usually used for grazing. }\end{array}$ \\
Wet land & Areas of land covered by perennial and intermittent water bodies.
\end{tabular}

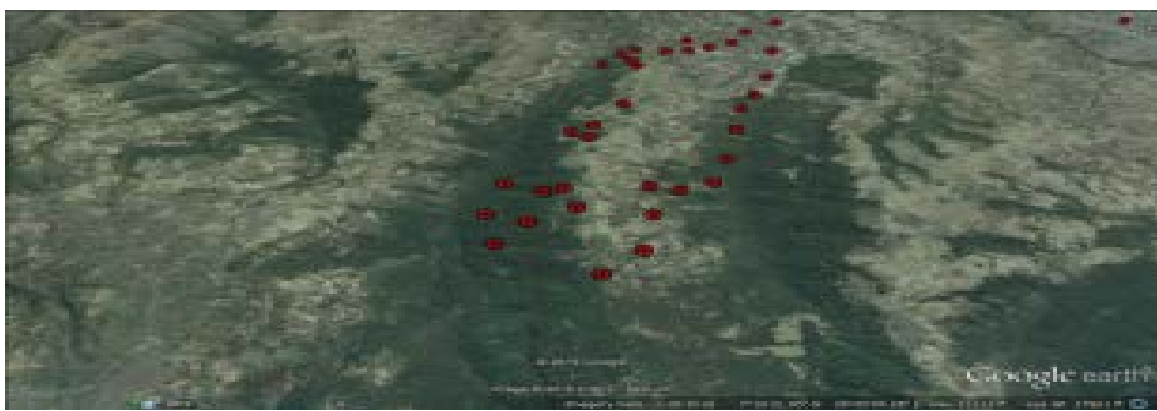

Figure 2. GCPs collected by the researcher during the field survey. 
spectrally different signature found for each information class. For example, an information class such as cultivated land contains several crop types, active agriculture and inactive agriculture areas, and each of them must be represented by several spectral classes. The researcher used more than thirty training samples for each classification. A recode function was used to merge spectrally different classes to generate final information classes. Landsat multispectral bands, except the thermal band, were used to identify the classes.

The post-classification approach was used for mapping detailed LULC determination. This approach is generally considered the most obvious approach to change detection [17]. It requires the comparison of independently classified images of the same study area acquired over two different time periods [18]. By properly coding the classification results for times 1976, 1995 and 2014, the analysis were produced a change map showing a complete matrix of changes (e.g. change from wetland to cultivated land and grassland to forest). Three land use/cover maps from 1976, 1995 and 2014 were produced using the ENVI 4.3 software.

\subsubsection{Accuracy Assessment of Supervised Classification}

Accuracy assessment is a procedure that compares a classified map against reference data or facts from the field to evaluate how well the classification represents the real world phenomena. An interpretation is then made of how closely the newly produced map from the remotely-sensed data matches the reference (base) map. For this purpose, the ground control points (GCPs) collected from field survey were superimposed to the classified maps and used to compare the value of facts from the field with the value of the classified map. This comparison produces error matrix which is the basis of accuracy assessment process (Table 3).

\subsubsection{Results of Accuracy Assessment}

Classified LULC maps from remotely sensed images may contain various types of errors. The confusion matrix presented in Table 3 shows the overall classification accuracies and accuracies of the single land-use/land cover classes.

The standard method of Confusion Matrix was used to assess classification accuracy for each image date by comparing classification results with ground truth region of interest (ROIs). The methods of accuracy assessment used included the Kappa statistic and Google Earth. The Kappa statistic is a statistical method of assessing the accuracy that took into account the chance of random agreement. Accordingly, the Kappa statistic average accuracy of classification was 78\%, 80\% and 93\% for 1976, 1995 and 2014 images respectively (Table 3). The result falls within the range of very good to excellent [19].

\subsection{Socio-Economic Data Collection Method}

Qualitative and quantitative data were collected by employing survey questionnaires, key informant interviews, and field observation to obtain reliable results. 
Table 3. Error matrix of land use/land cover maps derived from Landsat images.

\begin{tabular}{|c|c|c|c|c|c|c|c|c|c|}
\hline \multicolumn{8}{|c|}{ Reference Data } & \multirow{3}{*}{$\begin{array}{c}\text { Producer's } \\
\text { Accuracy } \\
(\%)\end{array}$} & \multirow{3}{*}{$\begin{array}{c}\text { User's } \\
\text { Accuracy } \\
(\%)\end{array}$} \\
\hline & \multicolumn{7}{|c|}{ 1) 1976 (Landsat MSS) } & & \\
\hline & Data & 1 & 2 & 3 & 4 & 5 & Total & & \\
\hline & 1 & 94 & 5 & 2 & 0 & 0 & 101 & 83 & 93 \\
\hline & 2 & 6 & 113 & 4 & 0 & 0 & 123 & 93 & 92 \\
\hline & 3 & 10 & 4 & 80 & 2 & 0 & 96 & 88 & 83 \\
\hline & 4 & 3 & 0 & 5 & 53 & 0 & 61 & 96 & 87 \\
\hline & 5 & 0 & 0 & 0 & 0 & 14 & 14 & 100 & 100 \\
\hline & Total & 113 & 122 & 91 & 55 & 14 & 395 & & \\
\hline & \multicolumn{9}{|c|}{ Overall Accuracy $89 \%$, Kappa Statistic 0.85} \\
\hline & \multicolumn{9}{|c|}{ 2) 1995 (Landsat TM7) } \\
\hline & 1 & 100 & 3 & 2 & 7 & 0 & 112 & 81 & 89 \\
\hline & 2 & 6 & 91 & 7 & 3 & 0 & 107 & 93 & 85 \\
\hline & 3 & 10 & 4 & 97 & 2 & 0 & 113 & 84 & 86 \\
\hline \multirow[t]{3}{*}{$\begin{array}{c}\text { Classified } \\
\text { Map }\end{array}$} & 4 & 7 & 0 & 9 & 103 & 0 & 119 & 90 & 87 \\
\hline & 5 & 0 & 0 & 0 & 0 & 19 & 19 & 100 & 100 \\
\hline & Total & 123 & 98 & 115 & 115 & 19 & 470 & & \\
\hline
\end{tabular}

Overall Accuracy 87\%, Kappa Statistic 0.82

3) 2014 (Landsat $\mathrm{ETM}^{+} 8$ )

$\begin{array}{ccccccccc}1 & 94 & 3 & 2 & 7 & 0 & 106 & 80 & 89 \\ 2 & 6 & 100 & 7 & 3 & 0 & 116 & 93 & 86 \\ 3 & 10 & 4 & 91 & 2 & 0 & 107 & 83 & 85 \\ 4 & 7 & 0 & 9 & 77 & 0 & 93 & 87 & 83 \\ 5 & 0 & 0 & 0 & 0 & 24 & 22 & 100 & 100 \\ \text { Total } & 117 & 107 & 109 & 89 & 22 & 446 & & \\ \text { Overall Accuracy } & 86 \% \text {, Kappa Statistic } 0.81\end{array}$

Accordingly, socio-economic survey was conducted to collect data on causes and impacts of land use and land cover change. For this purpose five representative peasant administrations (PAs) were selected from the three agro-ecologies for household heads sample selection. From selected PAs, a total of 120 household heads were selected using random sampling techniques. Survey questionnaires were prepared in local language (Afan Oromo) for the interview and then translated into English for analysis. In addition to this, key informant interview was conducted along with field observation to obtain additional information on the long year experience of land use/land cover change deriving practices in the district. The collected household survey data was concerned with the current socio-economic activities of the study area whereas data collected from the elders concerned with trends, causes and effects of land use/land cover change that 
traced back to 1976 and 1995 and linked to the current existing situation.

\subsection{Data Analysis}

To analyze quantitative data of satellite imagery, ERDAS Imagine version 2014 and ArchGIS version 10.3 softwares were employed. Accordingly, the major land use/land cover classes for the three study periods were classified using ERDAS Imagine version 2014 and separately mapped using ArchGIS version 10.3 softwares and then, areal coverage of the major land use/land cover types for each mapping period were calculated both in hectares and percentages. The comparison between values of the LULC types was carried out toidentify the percentage change, trend and rate of change between the entire study periods, i.e. 1976 and 2014. The collected socio-economic data were analyzed both qualitatively and quantitatively. Quantitative socio-economic data were analyzed by SPSS version 16 software. Field observation and qualitative socio-economic data were analyzed qualitatively. And the results were compared with the major land use/land cover change maps generated for the three study periods.

\section{Results and Discussions}

\subsection{Land Use Land Cover Results}

Grazing land, agriculture, forest land, shrub and wet lands were the five major LULC classes generated from the three study periods of satellite data. Table 4 shows the status of the major land use/land cover types in the three periods under consideration.

The classification result of the 1976 image (Figure 6) showed that cultivated land constituted the largest proportion of land in the district with a value of $45 \%$, followed by forestland which accounts for $24 \%$. Grazing land and shrub land constituted $14 \%$ and $15 \%$ respectively. The remaining constituent of the study area, perhaps the least, is wetland with a value of $2 \%$ (Figure 3 ). The result shows that during the year 1995, the cultivated and grazing lands were proportionally

Table 4. Land use land cover change in 1976, 1995 and 2014 in Agarfadistric, Oromia.

\begin{tabular}{ccccccc}
\hline \multirow{2}{*}{ LULC Categories } & \multicolumn{3}{c}{ Absolute Area cover $\left(\mathrm{km}^{2}\right)$} & \multicolumn{2}{c}{ Cover changes between period (\%) } \\
\cline { 2 - 7 } & 1976 & 1995 & 2014 & $1976-1995$ & $1995-2014$ & $1976-2014$ \\
\hline Grazing land & 173.09 & 239.03 & 246.11 & 38 & 3 & 42 \\
Agriculture & 547.01 & 608.07 & 712.03 & 11 & 17 & 30 \\
Forest land & 294.21 & 147.02 & 103.06 & -50 & -30 & -65 \\
Shrub land & 179.02 & 200.02 & 135.04 & 12 & -32 & -25 \\
Wet land & 23.01 & 22.20 & 20.10 & -4 & -9 & -13 \\
Total & 1216.34 & 1216.34 & 1216.34 & & & \\
\hline
\end{tabular}

${ }^{\star}$ Cover change between period was computed as $\left(\frac{A_{f}-A_{i}}{A_{i}}\right) \times 100$ where $A_{f}$ is Area of final year and $A_{i}$ is Area of initial year. 
increased to $50 \%$ and $20 \%$, respectively (Figure 4 ). To the contrary, the coverage of forest and wet lands was diminished to $12 \%$ and $2 \%$, in that order. Shrub land was exceptionally increased to $16 \%$ most likely due to gain from some of the forest land conversion to it. Land-use land-cover classification map is presented in Figure 3 which indicates that in year 2000 a shrub land accounts for $30 \%$ of a total area of the District. It was the largest proportion of land cover in year 2000. Farmland occupies the second place with $23 \%$ while the woodland comprises about $22 \%$. The forest class consisted $19 \%$ of the total area and followed by the bare-land and settlement which account for a proportion of $4 \%$ and $2 \%$, respectively (Table 5).

In the later period of the study, in 2014, the cultivated land is still the dominant class with areal coverage of $59 \%$ of the landscape. Similarly, grassland kept on increasing and reached $20 \%$ during this period (Figure 5). Contrastingly, the forest coverage was decreased to $8 \%$ while shrub and wet lands were respectively

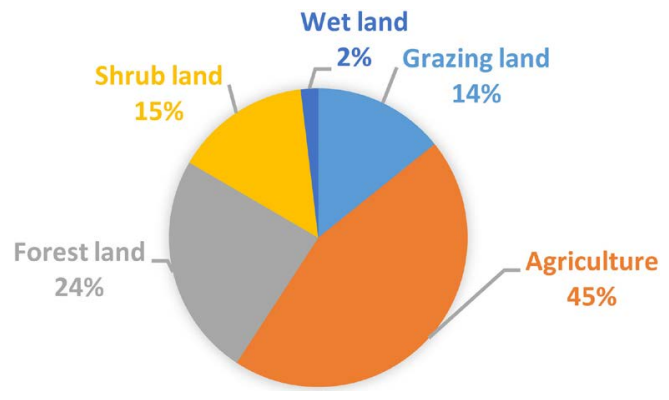

Figure 3. Graphical representation of LULC class proportion in the 1976.

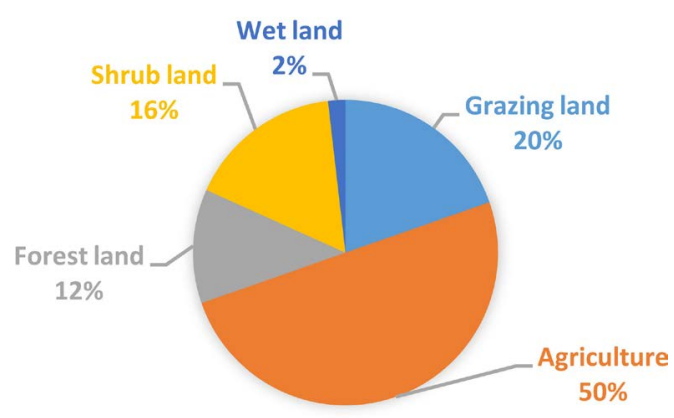

Figure 4. Graphical representation of LULC class proportion in the 1995.

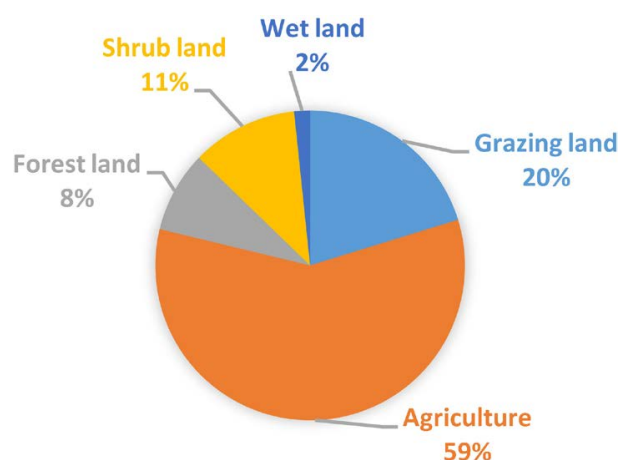

Figure 5. Graphical representation of LULC classes for the study year 2014 . 
become only $11 \%$ and $2 \%$ of the district's coverage due to anthropogenic activities and climate change.

The area once covered by shrub land was overwhelmed by grazing lands during 2014 compared to that of the 1995. There were also big shifts in spatial extent of grazing land to the southwestern part of the district encroaching to forest land.

In general, the result shows that the LULC of the study area had changed significantly during the period of 38 years (Figures 6-8). A rapid loss of forest land and shrub land cover in the landscape took place between 1976 and 2014. During the course of 38-years, the proportion of grazing land and the area of cultivated land have increased (Table 3). Although wet land area still covered a small proportion of the landscape in 2014, its proportion is declining due to climate changes most likely. The increase in cultivated land cover was large during the time period between 1995 and 2014 compared to the earlier time period between 1976 and 1995, whereas forest land and shrub land in contrast saw declines in the later period. Wet land decreased moderately, whereas shrub and forest lands cover showed drastic change during the 38-year period. Although it recovered between 1976 and 2014, grazing land cover was reduced in the later period, 1976-1995 (Table 3). Shrub land increased between 1976 and 1995, but then declined between 1995 and 2014 (Table 3). Figure 6 show the classified land use/land cover maps of the study area during 1976.

\subsection{LULC Change Evaluation}

Change detection is an important aspect to determine what is actually changing to what. That is, which land use/land cover classes were changing into which

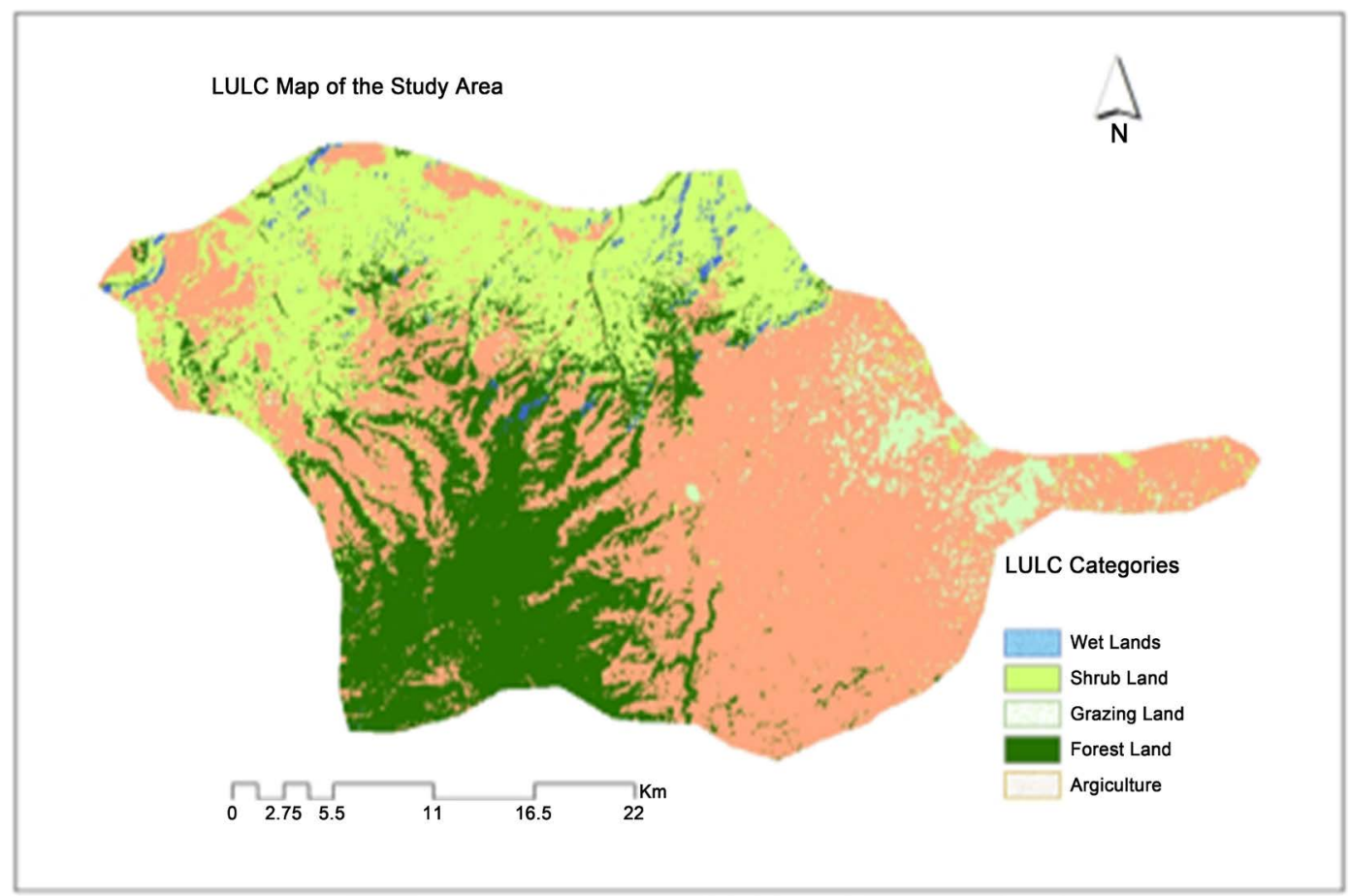

Figure 6. LULC maps for the years 1976 of the study area. 


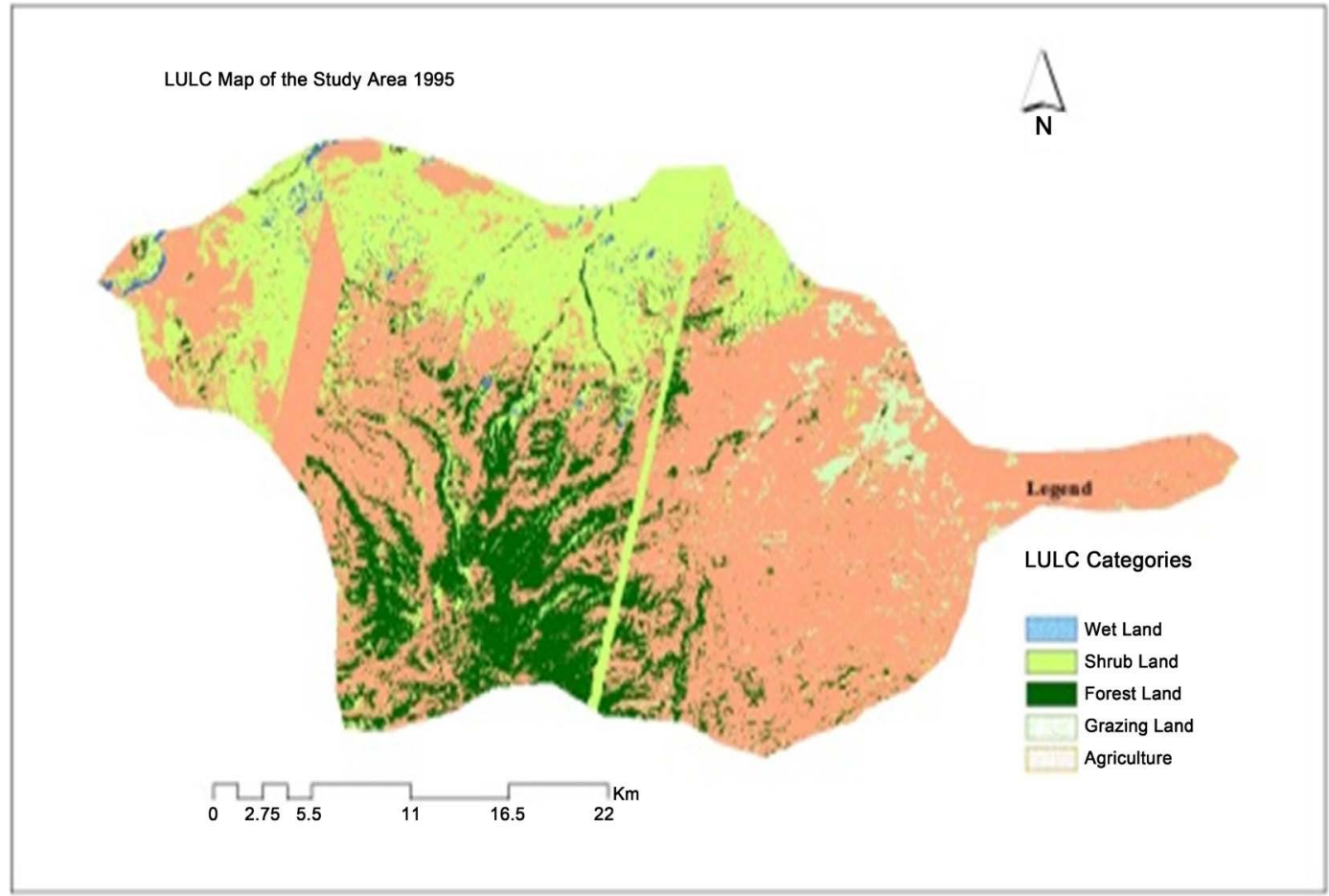

Figure 7. LULC maps for the years 1995 of the study area.

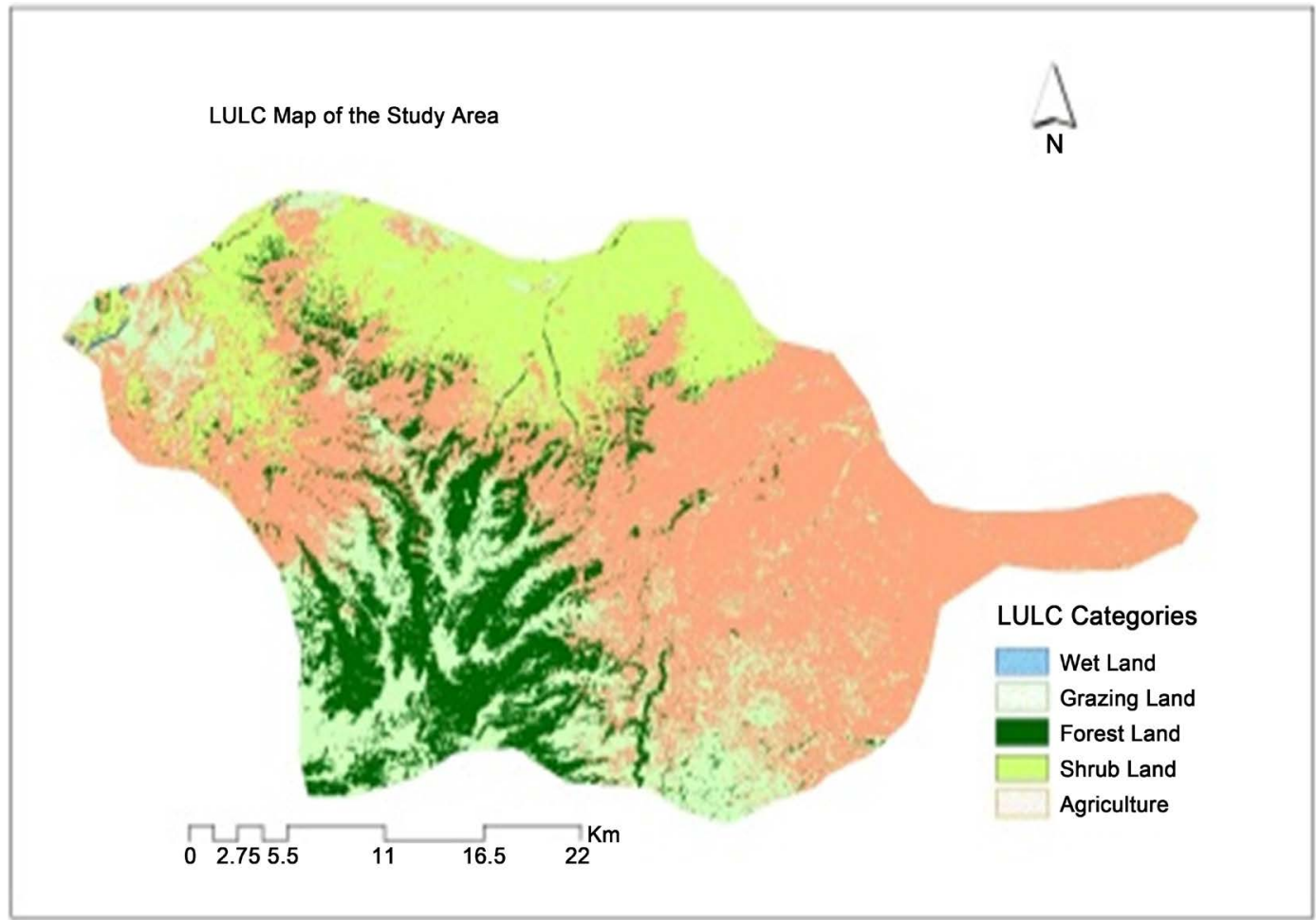

Figure 8. LULC maps for the years 2014 of the study area.

other classes? This information reveals both changes (increment and decrement) and persistence to change overtime. Such kind of information is of vital importance for decisions makers at many levels for natural resources management 
[20]. The land-use/land cover changes between the three periods (i.e. 1976, 1995 and 2014) were quantified and a change detection matrix of "from-to" change was derived to show land cover class conversion transitions during the 38-year period by overlaying the 1976 and 2014 images. After assigning integer values for each land use/land cover class as $1=$ Grazing land, $2=$ Agriculture, $3=$ For est land, $4=$ Shrub land and $5=$ Wet land, cross tabulation was employed to determine magnitude of conversions from a given land cover to another category at the later date [21]. This is called the transition probability matrix which shows net change and net change-to-persistence ratio [20] giving an impression to the resistance and vulnerability of a given land-use/land cover type. The transition probability matrix records the probability that each land cover category will change to the other category. This matrix is produced by the multiplication of each column in the transition probability matrix by the number of cells of corresponding LULC in the later image. For the 5 by 5 matrix table presented below, the rows represent the older land cover categories (1976) and the column represents the newer categories (2014) (Table 5 and Figure 9).

The "from-to" analysis result shows that the forest land and shrub land in the

Table 5. Transition matrix showing major changes in the landscape in Agarfa, 1976-2014.

\begin{tabular}{cccccccc}
\hline & \multicolumn{7}{c}{ To final state (2014) } \\
\cline { 2 - 7 } & Grazing & Agriculture & Forest & Shrub & Wetland & Total 1976 & Loss \\
\hline Grazing & $\mathbf{0 . 7 3}$ & 0.46 & 0 & 0.22 & 0.05 & 1.46 & 0.73 \\
Agriculture & 0.09 & $\mathbf{0 . 8 9}$ & 0 & 0.05 & 0 & 1.03 & 0.14 \\
Forest & 0.23 & 0.87 & $\mathbf{0 . 0 8}$ & 0.74 & 0 & 1.92 & 1.84 \\
Shrub & 0.73 & 0.89 & 0 & 0.09 & 0.32 & 2.03 & 1.94 \\
Wet land & 0 & 0.07 & 0 & 0.04 & 0.34 & 0.45 & 0.11 \\
Total 2014 & 1.78 & 3.18 & 0.08 & 1.14 & 0.71 & $2.13^{1}$ & \\
Gain & 1.05 & 2.29 & 0.08 & 1.05 & 0.37 & & \\
Net change & 0.32 & 2.15 & -1.76 & -0.89 & 0.26 & & \\
Net persistence & 0.44 & 2.41 & -22.00 & -9.89 & 0.76 & & \\
\hline
\end{tabular}

${ }^{1}$ Summation of the main diagonal elements represents the overall persistence of land cover; ${ }^{2}$ Net change = Gain - Loss; ${ }^{3} \mathrm{Net}$ persistence refers to net change to persistence ratio (i.e. net change/values along the main diagonal corresponding to each class).

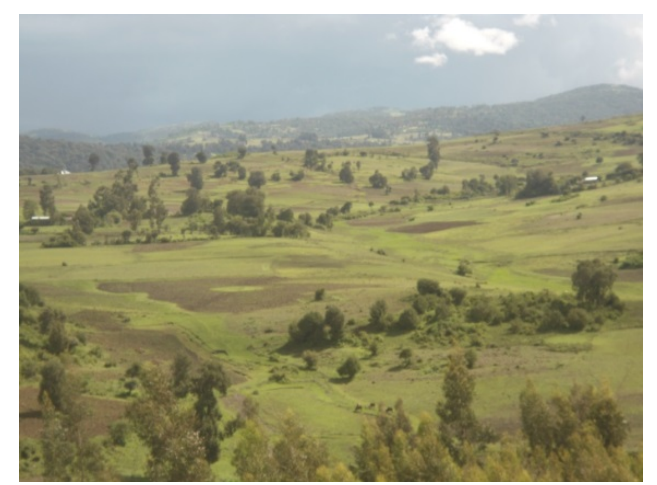

Figure 9. Agriculture penetrated into the very heart of the forested area (photo: by researcher). 
landscape were mainly converted to agriculture and grazing land during the period between 1976 and 2014 (Table 5). The largest portion of forest land was mainly converted into grazing land in the later period of the study. Forest, shrub and grazing lands were mainly converted to agriculture. At the same time, an equivalent area of grazing land was mutated to shrub and other land covers. The greatest net increase was attained by agriculture, primarily due to a huge conversion from forest and shrub cover types (Table 5).

As shown in Table 5, grazing land has a probability of 0.73 for remaining grassland and 0.46 of changing to agriculture in 2014. Likewise, each value indicated in Table 5 along the main diagonal of the matrix represents proportions of each land use/land cover class that was static during the study period. The loss column and gain row indicated the proportion of landscape that experienced gross loss and gain in each class, respectively. It is the difference between the total and persistence.

The net change-to-persistence ratio was large for shrub land (negative), agriculture (positive), forest land (negative) and grazing land (positive) indicating the most dominant trends in the changing landscape (Table 5). The net change-to-persistence ratio is closer to zero for the wet land-use/cover class, indicating that it had a higher tendency to persist rather than decline or increase (Table 5). The natural vegetation cover types, forest and shrub lands, have experienced low persistence, whereas grazing and cultivated lands have shown more persistence than other cover types (Table 5).

\subsection{Causes of Land Use/Land Cover Change and Its Socio-Economic Implications}

To further understand the dynamics of land use/land cover change, possible major drivers and consequences of the changes on environment and socio-economic conditions of the study community were explored using household heads and key informants.

Accordingly, majority (79\% - 99\%) of respondent household heads agreed that human population growth, drought, over grazing, increase in number of cattle, charcoal production, settlement and agricultural land expansion and increased need for fire wood were the major causes of land use land cover change in the study district. It was compared the responses of male and female respondents to see the mean difference between them. The result revealed that there was no statistically a significant difference between male and female household heads responses (Table 6). Therefore, it can be inferred that all these factors have contributed to observed land use/cover change at various degree in the study area.

With the regard to the effects of land use and land cover change on the local environment and livelihoods of the community, almost the majority of the respondents pointed out that there was a decline in agricultural productivity yield/productivity (79\%), trends of livestock size overtime $(84 \%)$ and stream flow or drying-up (85\%); scarcity of construction materials (82\%) and fuel wood (81\%); increase of runoff (88\%)and local climate change (79\%) respectively, over 
Table 6. Respondents' opinion results on causes of land use/cover change.

\begin{tabular}{|c|c|c|c|c|c|c|c|c|c|c|c|c|c|c|c|c|}
\hline \multirow{3}{*}{ No. } & \multirow{3}{*}{ Item } & \multicolumn{10}{|c|}{ Scale of response } & \multicolumn{5}{|c|}{ Independent $t$ test } \\
\hline & & \multicolumn{2}{|c|}{ SD } & \multicolumn{2}{|c|}{ DA } & \multicolumn{2}{|c|}{$\mathrm{U}$} & \multicolumn{2}{|c|}{ A } & \multicolumn{2}{|c|}{ SA } & \multirow{2}{*}{ Sex } & \multirow{2}{*}{$\mathrm{N}$} & \multirow{2}{*}{ M } & \multirow{2}{*}{ SD } & \multirow{2}{*}{ t-value } \\
\hline & & $\mathrm{F}$ & $\%$ & $\mathrm{~F}$ & $\%$ & $\mathrm{~F}$ & $\%$ & $\mathrm{~F}$ & $\%$ & $\mathrm{~F}$ & $\%$ & & & & & \\
\hline \multirow{2}{*}{1.} & \multirow{2}{*}{ Human population growth } & \multirow[t]{2}{*}{18} & \multirow{2}{*}{12.6} & \multirow{2}{*}{ - } & \multirow{2}{*}{ - } & \multirow{2}{*}{3} & \multirow{2}{*}{2.1} & \multirow{2}{*}{72} & \multirow{2}{*}{50.3} & \multirow{2}{*}{27} & \multirow{2}{*}{18.9} & M & 80 & & 1.0860 & \multirow{2}{*}{-1.776} \\
\hline & & & & & & & & & & & & $\mathrm{F}$ & 40 & 3.8750 & 1.1022 & \\
\hline \multirow{2}{*}{2.} & \multirow{2}{*}{ Drought } & \multirow{2}{*}{-} & \multirow{2}{*}{ - } & & & & & & & & & & & 3.2750 & 1.1035 & \\
\hline & & & & - & - & 3 & 2.1 & 52 & 36.4 & 45 & 60.4 & & & 3.4100 & 1.0132 & -1.234 \\
\hline & & & & & & & & & & & & & & 3.7750 & 1.0185 & \\
\hline 3. & Over grazing & 10 & 7.0 & 7 & 4.9 & 7 & 4.9 & 60 & 42.0 & 36 & 25.2 & & & 4.0750 & 1.3846 & -1.7754 \\
\hline 4 & Increase in number of cattle & 4 & 28 & 6 & 42 & 8 & 56 & 66 & 462 & 36 & 252 & & & 3.6875 & 1.0860 & -1667 \\
\hline & & & & & & & & & & & & & & 4.1000 & 1.5980 & \\
\hline 5 & Chorcol norduction & 6 & 12 & 17 & 110 & 6 & $=12$ & 55 & 205 & 26 & 252 & & & 3.7750 & 0.92743 & 555 \\
\hline 5. & Cnar coal production & 0 & 4.2 & 17 & 11.9 & 0 & 4.2 & 55 & 38.5 & 36 & 25.2 & & & 3.9000 & 1.5325 & -.553 \\
\hline & & & & & & & & & & & & & & 3.7625 & 1.0218 & \\
\hline 6. & Settlement expansion & 11 & 7.7 & - & - & 14 & 9.8 & 59 & 41.3 & 36 & 25.2 & & & 4.2000 & 1.2444 & -2.053 \\
\hline 7 & 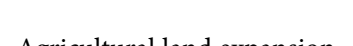 & 6 & & & & & & & & & 250 & & & 3.8875 & 0.85675 & 1204 \\
\hline 7. & Agricultural land expansion & 6 & 4.2 & 6 & 4.2 & 10 & 7.0 & 62 & 43.4 & 36 & 25.2 & & & 4.1250 & 1.2847 & -1.204 \\
\hline 8 & Increaced need for fire wod & 10 & 70 & 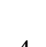 & 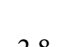 & 0 & 56 & 60 & 124 & 26 & 250 & & & 3.8375 & 0.96053 & \\
\hline 8. & Increased need for fire wood & 10 & 7.0 & 4 & 2.8 & 8 & 5.6 & 62 & 43.4 & 36 & 25.2 & & & 4.0750 & 1.3846 & -1.096 \\
\hline
\end{tabular}

Table value of $\mathrm{t}$-test $=1.98$ at 0.05 significance level with 118 degree of freedom.

Table 7. Respondents' opinion results on the socio-economic effects of land use/land cover change.

\begin{tabular}{|c|c|c|c|c|c|c|c|c|c|c|c|c|c|c|c|c|}
\hline \multirow{3}{*}{ No. } & \multirow{3}{*}{ Item } & \multicolumn{10}{|c|}{ Scale of response } & \multicolumn{5}{|c|}{ Independent $t$ test } \\
\hline & & \multicolumn{2}{|c|}{ SD } & \multicolumn{2}{|c|}{ DA } & \multicolumn{2}{|c|}{$\mathrm{U}$} & \multicolumn{2}{|c|}{$\mathrm{A}$} & \multicolumn{2}{|c|}{ SA } & \multirow{2}{*}{ Sex } & \multirow{2}{*}{$\mathrm{N}$} & \multirow{2}{*}{ M } & \multirow{2}{*}{ SD } & \multirow{2}{*}{$\mathrm{t}$-value } \\
\hline & & $\mathrm{F}$ & $\%$ & $\mathrm{~F}$ & $\%$ & $\mathrm{~F}$ & $\%$ & $\mathrm{~F}$ & $\%$ & $\mathrm{~F}$ & $\%$ & & & & & \\
\hline 1 & $\begin{array}{c}\text { Trend of yield/productivity } \\
\text { decrease }\end{array}$ & 10 & 7.0 & 4 & 2.8 & 11 & 7.7 & 59 & 41.3 & 36 & 25.2 & $\begin{array}{l}\mathrm{M} \\
\mathrm{F}\end{array}$ & $\begin{array}{l}80 \\
40\end{array}$ & $\begin{array}{l}3.800 \\
4.075\end{array}$ & $\begin{array}{r}0.97305 \\
1.3846\end{array}$ & -1.261 \\
\hline 2 & $\begin{array}{l}\text { Trends of livestock size } \\
\text { overtime decrease }\end{array}$ & 10 & 7.0 & 7 & 4.9 & 2 & 1.4 & 65 & 45.5 & 36 & 25.2 & & & $\begin{array}{l}3.800 \\
4.150\end{array}$ & $\begin{array}{l}1.0113 \\
1.3502\end{array}$ & -1.593 \\
\hline 3 & $\begin{array}{l}\text { Scarcity of construction } \\
\text { materials }\end{array}$ & 5 & 3.5 & 8 & 5.6 & 9 & 6.3 & 62 & 43.4 & 36 & 25.2 & & & $\begin{array}{l}3.900 \\
4.100\end{array}$ & $\begin{array}{c}0.82062 \\
1.3165\end{array}$ & -1.021 \\
\hline 4 & $\begin{array}{l}\text { Stream flow decreased or } \\
\text { dried-up }\end{array}$ & 9 & 6.3 & 7 & 4.9 & 2 & 1.4 & 66 & 46.2 & 36 & 25.2 & & & $\begin{array}{l}3.887 \\
4.075\end{array}$ & $\begin{array}{r}0.85675 \\
1.3846\end{array}$ & -.913 \\
\hline 5 & Scarcity of fuel wood & 9 & 6.3 & 1 & .7 & 13 & 9.1 & 61 & 42.7 & 36 & 25.2 & & & $\begin{array}{l}3.875 \\
4.075\end{array}$ & $\begin{array}{l}0.9463 \\
1.3847\end{array}$ & -.930 \\
\hline 6 & Runoff increased & 14 & 9.8 & - & - & - & - & 68 & 47.6 & 38 & 26.6 & & & $\begin{array}{l}3.825 \\
4.250\end{array}$ & $\begin{array}{l}1.0765 \\
1.3155\end{array}$ & -1.890 \\
\hline 7 & Local climate change & 14 & 9.8 & - & - & 11 & 7.7 & 69 & 48.3 & 26 & 18.2 & & & $\begin{array}{l}3.675 \\
3.975\end{array}$ & $\begin{array}{l}1.0406 \\
1.3298\end{array}$ & -1.354 \\
\hline
\end{tabular}

Table value of t-test $=1.98$ at 0.05 significance level with 118 degree of freedom. 
the past years (Table 7). The researcher compared the responses of male and female respondents to see the mean difference between them. The t-test value reveals that there is no significant difference between the male and female respondents (Table 7). Therefore, from the above finding it can be inferred that land use/cover change has attributed to the degradation of environmental/natural resource and its impacts on the livelihoods of the community in the study area.

\subsection{Discussion}

Agarfa district, one of the most fertile districts in southwestern part of Bale zone, has experienced substantial and increasing rates of land-use/land cover changes during 38 years from 1976 to 2014. During the course of this period, an area of around $191 \mathrm{~km}^{2}$ of forest lands was converted to agricultural areas and human settlements. These agricultural lands were prominently spread in the south-eastern and eastern parts of the district since the 1995. Shrub land losses were also accounted in the course of overgrazing. Approximately $65 \mathrm{~km}^{2}$ of shrub lands were lost during the study period. There have been persistent changes, both spatially and temporally, resulting in 55\% of the total area experiencing transitional changes among the land cover types. The poor vegetation cover observed in 2014 compared to 1976 and 1995 indicates that most of the vegetation types have been suffering from the influence of anthropogenic activities. Grazing land cover increased, particularly in the hills and steep slope escarpments, indicates a pervasive degradation of forest as the result of settlement encroachments.

In the time spanning from 1976 to1995, the overall net transition to less vegetation (i.e. grazing and cultivated land) covered about $847 \mathrm{~km}^{2}$, showing the impact of climate change, drought and related causes. During this period, a rapid loss of forest land was mainly caused by the severe droughts in 1973/74 and 1984/85 [22]. There was also a change in the land tenure system in 1975 following down fall of Hailesillasie regime that encouraged crop production on either an individual basis or through the establishment of farmers' cooperatives [23]. These events were important underlying causes of the land use/land cover changes in the study area.

As a result of continued population growth in the area together with the increased expansion of agricultural lands, more other land cover types were converted to cropland in the second period (1995-2014) of land use/land cover alterations. In this period, the net transition to less vegetation cover was $958 \mathrm{~km}^{2}$, indicating ever-increasing human pressure on natural resources.

Alike other areas of East Africa [24], agricultural expansion has been one of the key driving forces behind the land use/land cover changes in the study area. Even though cultivation is seen by some as a better livelihood strategy [25] stemming from increasing population and changes in relative prices between input and output [26], it is viewed as an unsustainable option by others [27] in terms of natural resources degradation. From the result of socio-economic data analysis made it was found that land use/land cover change was mainly caused 
due to significantly booming population growth, increased demand for agricultural land and settlement expansion, heightened demand for fuel wood and char coal extraction, over grazing and to a lesser extent drought(mainly rainfall variability) (Figure 10(a) and Figure 10(b)).

The fact that agriculture constituted the highest proportion of the landscape in this period is partly attributable to changes in the tenure system from being the land was owned by the land lord feudal before 1974 to land for tillers system in the Derg. However, according to the elder informants, owing to intact resource conservation culture of Arsi Oromo inhabitants in the area, deforestation was minimum during this period, and forest land was the second largest cover type. The population density in the district was also too low to impose a heavy pressure to alter the land use/land cover types.

According to the informants and local administrators, increased agricultural expansion as the result of population booming and land tenure change (landfor-tillers) in the 70s took place. During the transition period from Derg to EPRDF in the 1990s, there was a high rate of deforestation on the natural forest. Increased land degradation following the extreme droughts of the 1973/74 and $1984 / 85$ has contributed a lot for the land use land cover changes in the study area.

The informants stated that firewood extraction and timbering are the main causes of forest land cover reduction as a high surge of population are highly involved in charcoal and firewood sale in addition to crop production. The informants also added that forest and shrub lands were highly exploited for the purposes of household energy consumption (like firewood and charcoal production) and house construction.

In general, people stated that the changes in land use/land cover mainly caused by high population pressure, extreme climate condition such as droughts and increasing numbers of dry years among other drivers, highly affected their livelihoods and have made tremendous change to land use land cover patterns over the last four decades.

From the responses of the interviewees it was found that several socio-economic effects were emanated from changing land use/land cover in the study area. Among

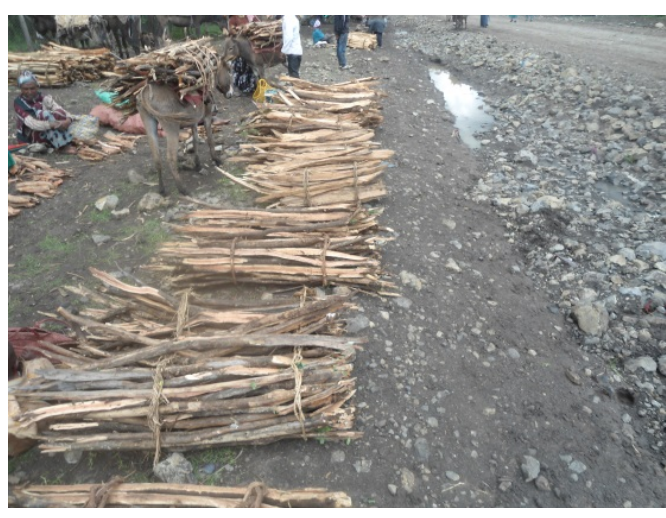

(a)

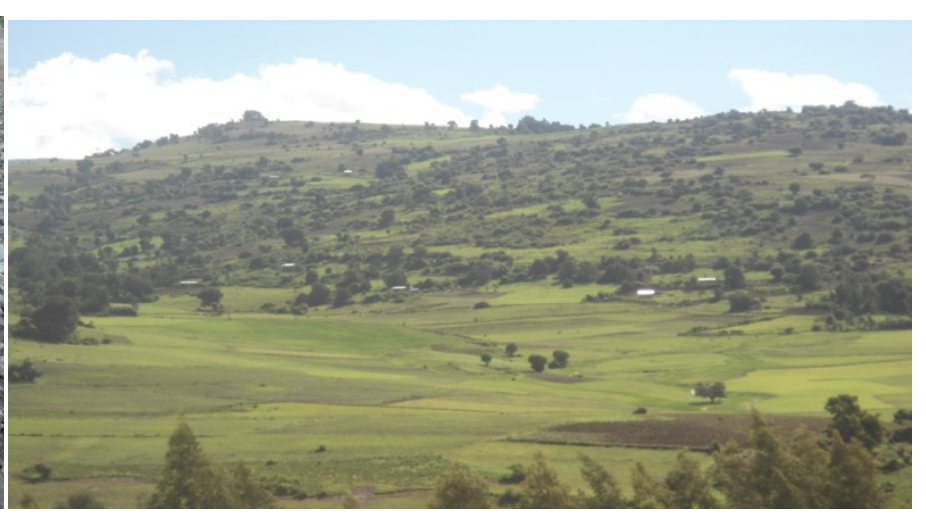

(b)

Figure 10. (a) Fuel wood on the market; (b) agriculture and settlement expansion into the forest. 
others, declining productivity particularly on hilly areas owing to reduced soil fertility which was caused by severe soil erosion in the area (Figure 11(a) and Figure 11(b)).

The other socio-economic impacts of the land use cover change were scarcity of fuel wood, construction materials and decline in livestock number which in turn has implication on household income. Increased run off is also the other effect of land use/cover change in the study area that causes the most serious type erosion (gully erosion) in the study area.

\section{Conclusions}

In this research an attempt was made to develop comprehensive LULC maps of Agarfa district for three distinct years spanning from 1976 to 2014 for the evaluation of spatio-temporal changes. Satellite imageries from Landsat data proved to be adequate source for the analysis of large and fast changing in agro-rural setup of the Agarfa district, in particular, the natural environments, in general.

Results have revealed that in the study area, the largest LULC was occupied by agriculture, which covers $45 \%, 50 \%$ and 59\% of entire area in 1976, 1995 and 2014, respectively. Its expansion to other land cover area was the main deriving factor for the LULC changes in the study area. At the end of this study period, other land cover types such as forest, shrub, wetlands and grazing areas occupied only $8 \%, 11 \%, 20 \%$ and $2 \%$ of entire study area, respectively. Even though many changes have observed among the LULCs in the year between 1976 and 2014, the highest rate of changes were seen in forest lands which was decreased by $65 \%$ and cultivated areas and grazing lands which were increased by $30 \%$ and $42 \%$, in that order. Despite excessive climate changes, wetlands were changed very slowly that they decreased by $2 \%$ through the course of the study period. The increase of agriculture and grazing lands were mainly at the expense of other land uses and this is attributed to population growth in the last 38 years.

\section{Recommendation}

The general trend observed in the study area implies a loss of natural forest and shrub land cover and an increase in cultivated areas and grazing land cover. The

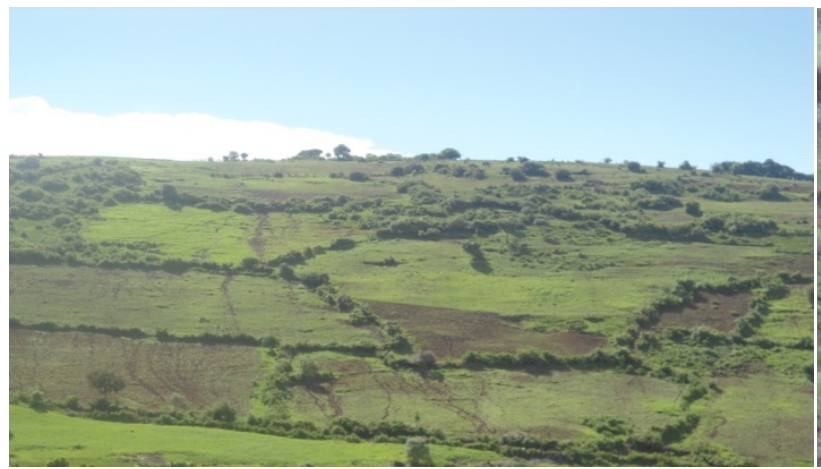

(a)

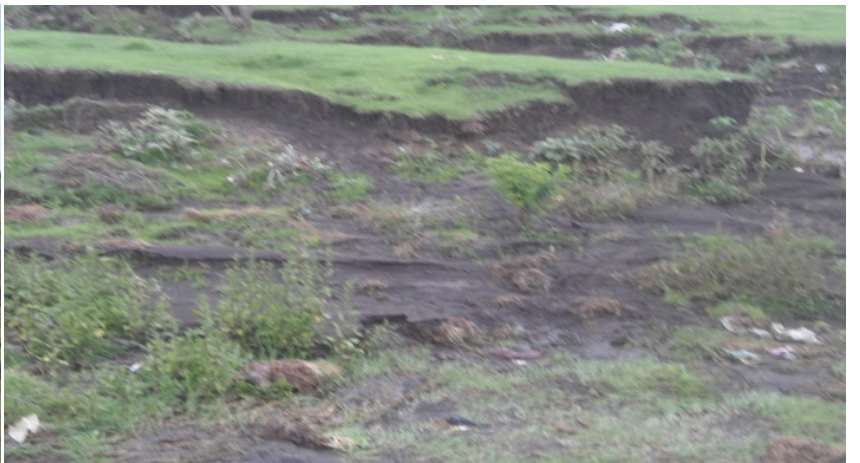

(b)

Figure 11. (a) Photo by researcher: soil erosion and (b) gully development on the hilly area. 
present tendency may lead to more land degradation if no assisted restoration is made. Continued land use/land cover change, coupled with an adverse effect of climate change, greatly affects people's livelihoods and puts the natural resources under heavy pressure. Therefore, based on the research findings of this study, the following way forwards are suggested for decision makers in many levels and future research directions:

- The provision of land use right to the landless group of community may encourage better management of natural resources.

- Improvement of non-timber products like apiculture and eco-tourism would lessen the deforestation rate and rather promote the reforestation schemes that would in turn help the climate resilient economic development strategy.

- Convincing communities to stop cultivating areas with steep slope would manage soil and water in the study area.

- In order to mitigate overgrazing in the study area, better livestock management system should be practiced.

\section{Conflicts of Interest}

The authors declare no conflicts of interest regarding the publication of this paper.

\section{References}

[1] Wu, J.J. (2008) Land Use Changes: Economic, Social and Environmental Impacts. Choices, 23, 6-10.

[2] Yeshaneh, E., Blöschl, G., Wagner, W. and Exner-Kittridge, M. (2013) Identifying Land Use /Cover Dynamics in the Koga Catchment, Ethiopia, from Multi-Scale Data, and Implications for Environmental Change. International Journal of GeoInformation, 2, 302-323.

[3] Maitima, J.M., Maitima, J.M., Mugisha, S. and Olson, J.M. (2010) Land Use Changes, Impacts and Options for Sustaining Productivity and Livelihoods in the Basin of Lake Victoria. Journal of Sustainable Development in Africa, 12, 189-190.

[4] Lambin, E.F., Geist, H.J. and Lepers, E. (2003) Dynamics of Land-Use and Land-Cover Change in Tropical Regions. Annual Review of Environment and Resources, 28, 205-241. https://doi.org/10.1146/annurev.energy.28.050302.105459

[5] EWCA and SDPAS (2009) The Value of the Protected Area System: Message to Policy Makers. SDPASE, EWCA, GIZ, UNDP, and GEF, Addis Ababa.

[6] Dupuy, J. (2009) GIS Analyst. Bale Eco-Region Sustainable Management Programmme.

[7] FAO (2010) Guidelines on Sustainable Forest Management in Dry Lands of sub-Saharan Africa.

[8] Nestenet, K. (2007) Land Use/land Cover Change in Herenna Forest and Surrounding Area, Bale Mountain National Park, Oromia Regional State, Ethiopia. Thesis (MA) Addis Ababa University, Addis Ababa.

[9] Teshome, E., Randall, D. and Kinahan, A.A. (2011) The Changing Face of the Bale Mountains National Park over 32 Years: A Study on Land Cover Change. Walia Journal of the Ethiopian Wildlife and Natural History Society, 2011, 118-130

[10] Yohannes, K., Reinhold, S. and Carl, B. (2012) Vegetation Dynamics, and Land Use 
and Land Cover Change in the Bale Mountains, Ethiopia. Environmental Monitoring and Assessment, 184, 7473-7489.

[11] Mesay, M. (2011) Land Use/Land Cover Dynamics in Nonno District, Central Ethiopia. Journal of Sustainable Development in Africa, 13, 123-141.

[12] Moshen, A. (1999) Environmental Land Use Change Detection and Assessment Using Muli-Temporal Satellite Imagery. Zanjan University, Iran.

[13] AWADOR Agarfa District Agriculture Development Office Report (Unpublished).

[14] The 2007 Population and Housing, Census of Ethiopia.

[15] Anderson, J.R., Hardy, E.E, Roach, J.T. and Witmer, R.E. (1976) A Land Use and Land Cover Classification System for Use with Remote Sensor Data. U.S. Gov't, Washington DC. https://doi.org/10.3133/pp964

[16] FAO (2012) Global Forest Land Use Chile. Rome.

[17] Liu, H. and Zhou, Q. (2004) Accuracy Analysis of Remote Sensing Change Detection by Rule-Based Rationally Evaluation with Post Classification Comparison. International Journal of Remote Sensing, 25, 1037-1050.

[18] Serra, P., Pons, X. and Sauri, D. (2003) Post Classification Change Detection with Data from Different Sensors: Some Accuracy Considerations. International Journal of Remote Sensing, 24, 3311-3340. https://doi.org/10.1080/0143116021000021189

[19] Monserud, R.A. and Leemans, R. (1992) Comparing Global Vegetation Maps with the Kappa Statistic. Ecological Modelling, 62, 275-293. https://doi.org/10.1016/0304-3800(92)90003-W

[20] Braimoh, A.K. (2006) Random and Systematic Land Cover Transitions in Northern Ghana. Agriculture, Ecosystems \& Environment, 113, 254-263. https://doi.org/10.1016/j.agee.2005.10.019

[21] Alphan, H. (2008) Land Use Change and Urbanization in Adana, Turkey. Land Degradation and Development, 14, 575-586. https://doi.org/10.1002/ldr.581

[22] Meze-Hausken, E. (2004) Contrasting Climate Variability and Methodological Drought with Perceived Drought and Climate Change in Northern Ethiopia. Climate Research, 27, 19-31. https://doi.org/10.3354/cr027019

[23] Congalton, R. (1991) A Review of Assessing the Accuracy of Classifications of Remotely Sensed Data. International Journal of Remote Sensing, 37, 35-46.

[24] Reid, R.S., Thornton, P.K. and Kruska, R.L. (2004) Loss and Fragmentation of Habitat for Pastoral People and Wildlife in East Africa: Concepts and Issues. African Journal of Range \& Forage Science, 21, 171-184. https://doi.org/10.2989/10220110409485849

[25] Campbell, D.J., Lusch, D.P., Smucker, T.A. and Wangu, E.E. (2005) Multiple Methods in the Study, of Driving Forces of Land Use and Land Cover Change: A Case Study of SE Kajiado District, Kenya. Human Ecology, 33, 763-794. https://doi.org/10.1007/s10745-005-8210-y

[26] Vedeld, P.O. (1995) Land Use and Deforestation in East Africa-Competing Uses under Labor and Market Constraints. Discussion Paper D-16/1995.

[27] Little, P.D., Mcpeak, J., Barrett, C.B. and Kristjanson, P. (2008) Challenging Orthodoxies: Understanding Poverty in Pastoral Areas of East Africa. Development and Change, 39, 587-611. https://doi.org/10.1111/j.1467-7660.2008.00497.x 